\title{
CORRECTION
}

\section{Correction to: The prenatal environment and risk for mental illness in young people}

Joshua L. Roffman and Erin C. Dunn (D)

(c) The Author(s), under exclusive licence to American College of Neuropsychopharmacology 2022

Neuropsychopharmacology (2022) 47:1140; https://doi.org/10.1038/s41386-021-01169-1

Correction to: Neuropsychopharmacology https://doi.org/10.1038/ s41386-021-01143-x, published online 18 August 2021

In this article, the title was incorrectly given as "Neuropsychopharmacology reviews 2022 hot topics: the prenatal environment and risk for mental illness in young people" but should have been
“The prenatal environment and risk for mental illness in young people"

rff

The original article has been corrected. 